\title{
Correction to: A novel murine model of multi-day moderate ethanol exposure reveals increased intestinal dysfunction and liver inflammation with age
}

Rachel H. McMahan ${ }^{1,2^{*}}$, Kevin M. Najarro ${ }^{1}$, Juliet E. Mullen ${ }^{1}$, Madison T. Paul', David J. Orlicky ${ }^{3}$, Holly J. Hulsebus ${ }^{1,4}$ and Elizabeth J. Kovacs ${ }^{1,2,4}$

Correction to: Immun Ageing 18, 37 (2021)

https://doi.org/10.1186/s12979-021-00247-8

Following publication of the original article [1], the authors reported a publishing error in which images from Fig. 3 were inserted into Fig. 4 (the last 6 images). The correct Fig. 4 is presented below.

The original article [1] has been updated.

The original article can be found online at https://doi.org/10.1186/s12979021-00247-8.

* Correspondence: Rachel.McMahan@CUAnschutz.edu

${ }^{1}$ Department of Surgery, Division of Gl, Trauma and Endocrine Surgery, and Alcohol Research Program, University of Colorado Denver, Anschutz Medical Campus, 12,700 East 19th Ave, RC2, Mail Stop \#8620, Aurora, CO 80045, USA

${ }^{2} \mathrm{Gl}$ and Liver Innate Immune Program, University of Colorado Denver, Anschutz Medical Campus, Aurora, CO 80045, USA

Full list of author information is available at the end of the article

(c) The Author(s). 2021 Open Access This article is licensed under a Creative Commons Attribution 4.0 International License, which permits use, sharing, adaptation, distribution and reproduction in any medium or format, as long as you give appropriate credit to the original author(s) and the source, provide a link to the Creative Commons licence, and indicate if changes were made. The images or other third party material in this article are included in the article's Creative Commons licence, unless indicated otherwise in a credit line to the material. If material is not included in the article's Creative Commons licence and your intended use is not permitted by statutory regulation or exceeds the permitted use, you will need to obtain permission directly from the copyright holder. To view a copy of this licence, visit http://creativecommons.org/licenses/by/4.0/ The Creative Commons Public Domain Dedication waiver (http://creativecommons.org/publicdomain/zero/1.0/) applies to the data made available in this article, unless otherwise stated in a credit line to the data. 


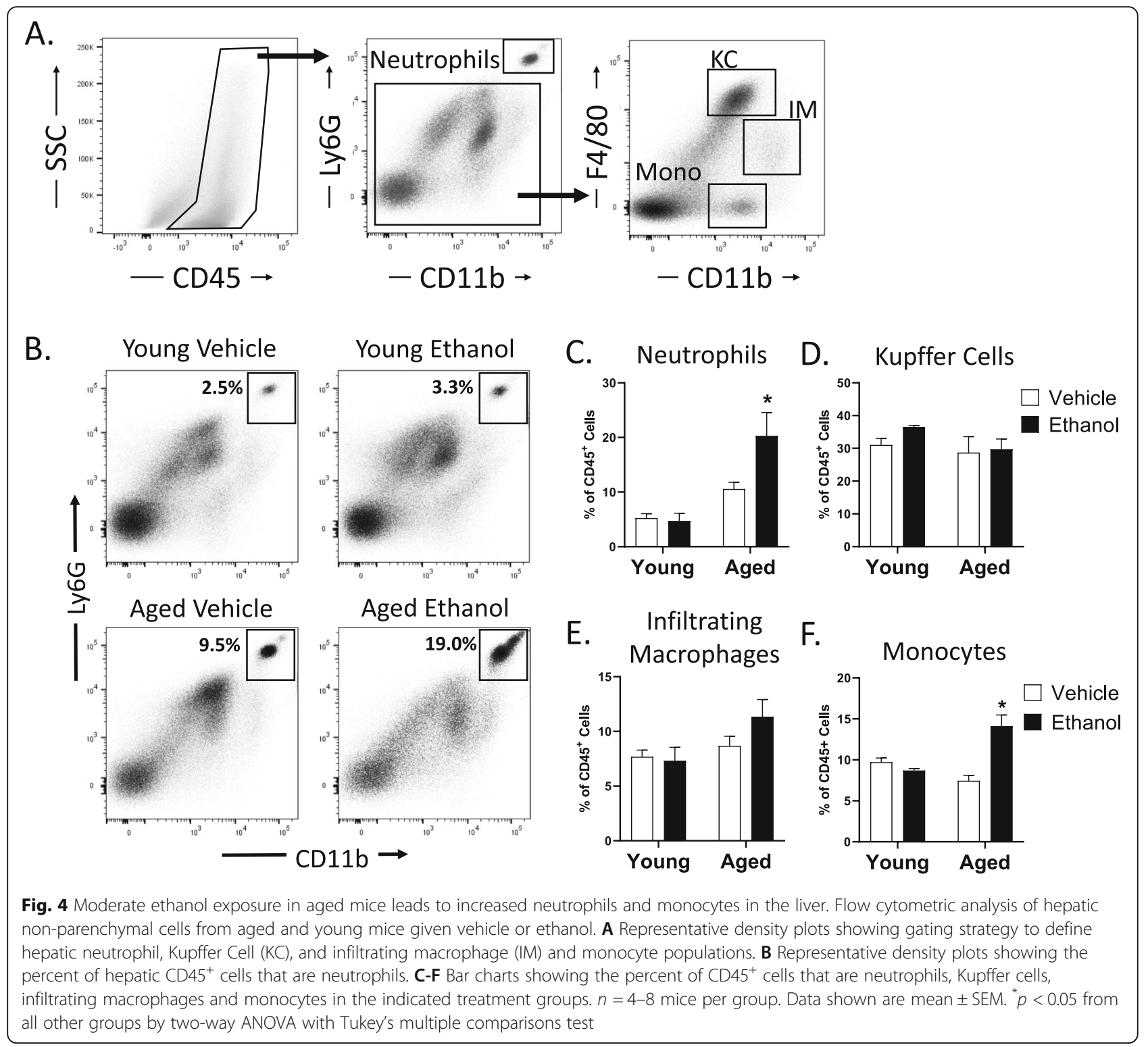

\section{Author details}

'Department of Surgery, Division of Gl, Trauma and Endocrine Surgery, and Alcohol Research Program, University of Colorado Denver, Anschutz Medical Campus, 12,700 East 19th Ave, RC2, Mail Stop \#8620, Aurora, CO 80045, USA. ${ }^{2} \mathrm{Gl}$ and Liver Innate Immune Program, University of Colorado Denver, Anschutz Medical Campus, Aurora, CO 80045, USA. ${ }^{3}$ Department of Pathology, University of Colorado Denver, Anschutz Medical Campus, Aurora, CO 80045, USA. ${ }^{4}$ Department of Immunology and Microbiology, University of Colorado Denver, Anschutz Medical Campus, Aurora, CO 80045, USA.

Published online: 21 October 2021

\section{Reference}

1. McMahan RH, Najarro KM, Mullen JE, Paul MT, Orlicky DJ, Hulsebus HJ, et al.

A novel murine model of multi-day moderate ethanol exposure reveals increased intestinal dysfunction and liver inflammation with age. Immun Ageing. 2021;18(1):37. https://doi.org/10.1186/s12979-021-00247-8. 